\title{
Arctic ground squirrel population collapse in the boreal forests of the Southern Yukon
}

\author{
Jeffery R. Werner ${ }^{\mathrm{A}, \mathrm{E}}$, Charles J. Krebs ${ }^{\mathrm{A}}$, Scott A. Donker ${ }^{\mathrm{B}}$, Rudy Boonstra ${ }^{\mathrm{C}}$ \\ and Michael J. Sheriff ${ }^{\mathrm{D}}$ \\ A Department of Zoology, University of British Columbia, 6270 University Boulevard, \\ Vancouver, BC V6T 1Z4, Canada. \\ ${ }^{B}$ Alberta Environment and Sustainable Resource Development, 9920108 Streeet, Edmonton, \\ AB T5K 2M4, Canada. \\ ${ }^{\mathrm{C}}$ Division of Life Sciences, University of Toronto at Scarborough, 1265 Military Trail, \\ Scarborough, ON M1C 1A4, Canada. \\ ${ }^{D}$ Department of Ecosystem Science and Management, Pennsylvania State University, \\ University Park, PA 16802, USA.

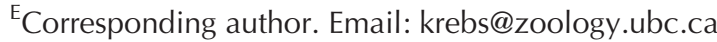

\begin{abstract}
Context. The arctic ground squirrel (Urocitellus parryii) comprised 17\% of the biomass of herbivores in the Yukon boreal forest during the summer months from 1987 to 1996 and was responsible for 23\% of the energy flow at the herbivore level. By 2000, ground squirrel populations in this region collapsed to nearly zero and have remained there.

Aims. We summarise the population monitoring (since 1975) and recent experimental work that has been done on this key herbivore in the Kluane area of the southern Yukon to test one mechanistic hypothesis as the possible explanation for this population collapse and subsequent lack of recovery: predation.

Methods. Ground squirrels are the preferred summer prey of bird and mammal predators when snowshoe hare (Lepus americanus) populations are declining. We used translocations into formerly occupied habitat and radiotelemetry to determine movements and causes of death from 2009 to 2014 . We surveyed 158 sites between 2008 and 2013 to measure the disappearance of colonies in alpine and forest habitats over $25000 \mathrm{~km}^{2}$.

Key results. Ground squirrels from 2000 to 2013 comprised a small fraction of the herbivore biomass in the boreal forest zone, down from 17\% earlier. Most forest populations ( 95\%) are currently extinct, whereas just over half (65\%) of low-elevation meadow populations are locally extinct. One hypothesis is that ground squirrels in the forest have been driven into a predator pit from which they cannot recover. They remain abundant in alpine tundra (93\% occupancy rate) and around airport runways and human habitations (97\% occupancy), but there is no apparent dispersal from alpine areas down into the boreal forest.

Conclusion. The predator pit hypothesis is a likely explanation for the initial collapse and sustained decline in population size from 2000 to 2013. Recent attenuation of the hare cycle and milder winter climate have allowed shrubs to expand throughout the forest, thereby reducing visibility and increasing predation risk. This conclusion will be tested in further research using reintroductions to formerly occupied sites.
\end{abstract}

Implication. If the loss of this herbivore from the boreal forest is not reversed, predator pressure on the other major herbivores of the montane forest zone is likely to change significantly.

Additional keywords: Allee effect, apparent competition, burrow flooding, climate change, conspecific attraction, dispersal, hibernacula, predation, predator pit, Urocitellus parryii.

Received 29 September 2014, accepted 16 January 2015, published online dd mmm yyyy

\section{Introduction}

Arctic ground squirrels (AGS) are a common small mammal in arctic and alpine tundra areas of northern Canada. One of the peculiarities of their geographic distribution is the extension of their range into the boreal forests of the Yukon (Fig. 1). The population dynamics of the AGS in the boreal forest in the Kluane Lake region of south-west Yukon have been followed since the 1970s (Hubbs and Boonstra 1997; Byrom et al. 2000; Karels et al. 2000; Gillis et al. 2005a; Donker and Krebs 2012). The characteristic feature of the population dynamics from the 


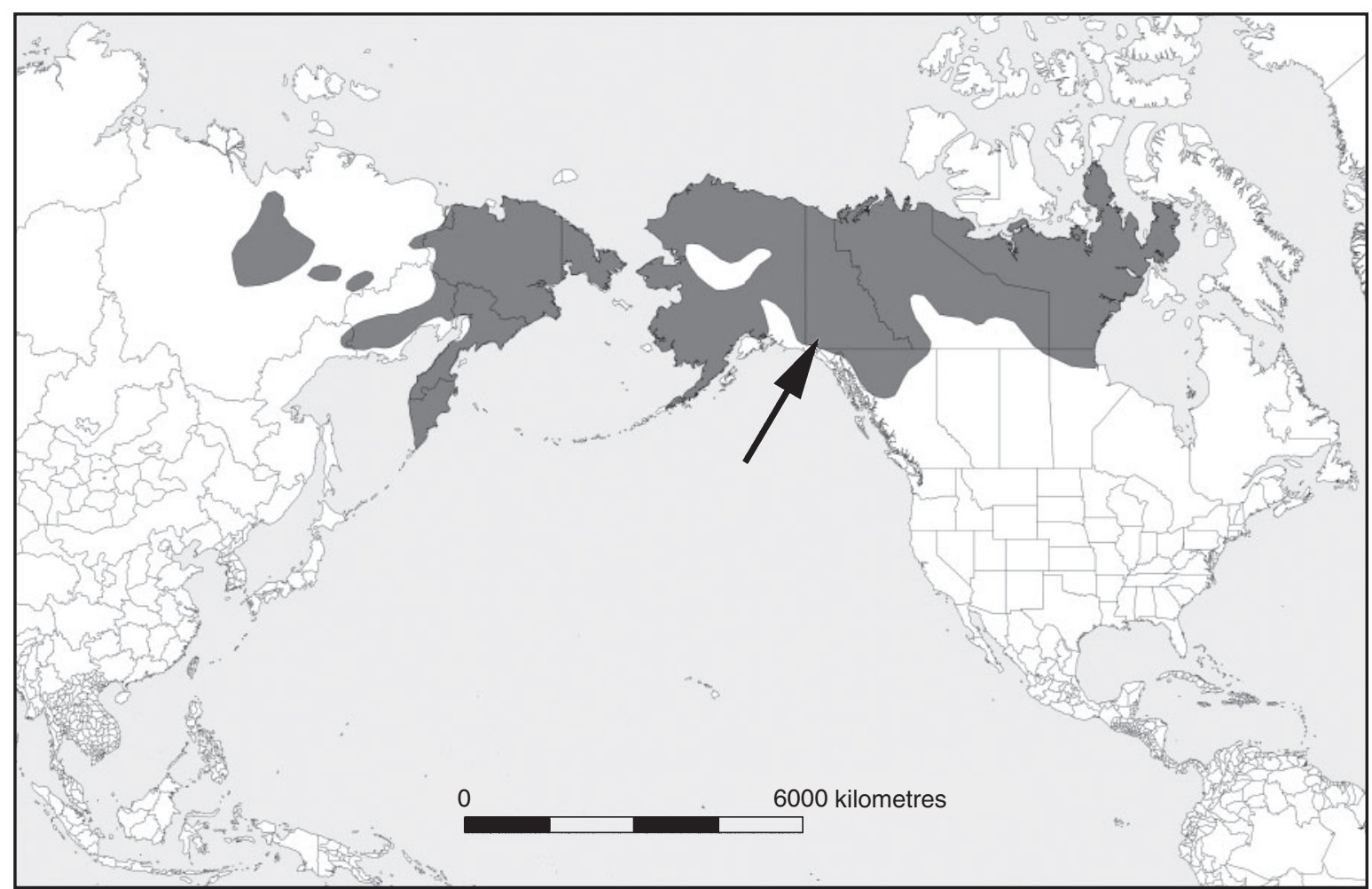

Fig. 1. Geographical range of the arctic ground squirrel (shaded area) and the location of our studies at Kluane Lake, Yukon (arrow). Source: IUCN (2008).

1970s to 1999 was a 9-10-year cycle in numbers that was related to the snowshoe hare cycle (Krebs et al. 2014). The numbers of AGS rose and fell during this period because they are alternative prey of the major hare predators, namely coyotes, Canada lynx and great-horned owls. However, after the snowshoe hare peak of 1998, AGS population density declined severely in the boreal forest by 2000, did not increase during the subsequent hare peak of 2006 and currently remains near zero. The question we address in this paper is why this collapse happened and whether it may be reversed.

AGS are a keystone species that directly or indirectly influences top-down and bottom-up ecological processes over large geographic scales in northern North America. They serve as an important prey item, herbivore and ecological engineer, and their distribution drives the abundance and spatial arrangement of other ecosystem components, ranging from top carnivores to plant communities (Wheeler and Hik 2012). In the boreal forest, AGS made up $17 \%$ of the vertebrate herbivore biomass and accounted for nearly one-quarter of the energy flow through the system (Krebs 2001), whereas in alpine tundra they may account for over half the energy moving through mammalian herbivores (Wheeler 2012).

AGS are the largest and most northerly distributed squirrel in North America. In arctic and subarctic regions they form permanent social colonies comprised of shallow burrow systems $(\sim 1 \mathrm{~m}$ depth) that provide refuge from predators and thermal stress and are used for maternal denning and overwinter hibernation (Carl 1971; McLean 1981). AGS are diurnal and consume a wide variety of grasses and forbs (Green 1977) during their 5-month (range 4-7 months) summer active season (late April-September) before hibernation (Sheriff et al. 2011). The species is territorial, and populations in the montane and arctic tundra are thought to be regulated by competition for suitable habitat (Carl 1971; Green 1977; Batzli and Sobaski 1980); however, in the boreal forest, populations were considered to be limited by an interacting combination of food and predators (Hubbs and Boonstra 1997), and regulated by density-dependent changes to overwinter survival and weaning success (Karels and Boonstra 2000). Nearly all males disperse within their first year of life, but females are philopatric and tend to settle near the natal site (Gillis 2003) unless critical resources become limiting, as has been observed under experimental conditions (Byrom and Krebs 1999). Poor survival of juvenile males contributes to female-biased adult sex ratios (Gillis 2003), and the social structure is considered to be largely polygynous (McLean 1981). A short single mating season occurs within a few days of female emergence in April (Buck and Barnes 1999; Sheriff et al. 2011, 2013).

Vegetation communities and soil compositions surrounding colony sites are strongly influenced by soil disturbance, selective foraging and food caching (Gillis et al. 2005b). These small mammals are a critical food source for falcons, owls, hawks, Canada lynx, coyotes, foxes, wolves and grizzly bears (Carl 1971; Byrom 1997; Gillis et al. 2005a; Donker and Krebs 2011). They are also hunted by Yukon First Nations as a traditional source of food. Therefore, population fluctuations of AGS regularly affect the food supply available to these predators (Byrom 1997; Donker and Krebs 2011). Prior to the 
population collapse, factors affecting the boreal forest population size were primarily related to changes in predation pressure, which, in turn, was influenced by snowshoe hare and alternative prey abundance (Gillis et al. 2005a).

In this paper we explore possible reasons for the collapse and lack of recovery of AGS populations in the forests of the southern Yukon after 2000. The scope of the present discussion is limited to the montane boreal forest of North America, the only portion of Canada's boreal forest that is inhabited by arctic ground squirrels. We estimated abundance across a large region of southwestern Yukon using mark-recapture within different habitat types and broad-scale abundance surveys. We used experimental transplants into historically occupied low-elevation habitat to help us better understand the inability of AGS to recover from their current low densities. We hypothesise that predation was the proximate cause of this collapse, and that forest populations may now be in a predator pit preventing recovery. In addition, climate change may have made it lethal to hibernate in the forest because of winter and early spring rains associated with global warming. Finally, we discuss the critical need to understand the lack of recovery of AGS populations, which may be due to their inability to colonise extinct sites.

\section{Materials and methods}

This research was approved by the University of British Columbia Animal Care Committee in accordance with the guidelines of the Canadian Council on Animal Care.

\section{Study area}

AGS occupy three distinct habitat types (boreal forest, lowelevation meadow and alpine meadow) in the Kluane Region of the Yukon Territory, Canada. Population data were collected at four grids: two boreal forest sites (1975-present), one lowelevation meadow site (2008-09) and one alpine meadow site (2008-09). In the boreal forest, most data were collected at two 10 -ha grids located approximately $20 \mathrm{~km}$ from each other ( $\sim 900 \mathrm{~m}$ above sea level (a.s.1.); $61^{\circ} 00^{\prime} 38^{\prime \prime} \mathrm{N}, 138^{\circ} 11^{\prime} 31^{\prime \prime} \mathrm{W}$ and $60^{\circ} 55^{\prime} 53^{\prime \prime} \mathrm{N}, 137^{\circ} 58^{\prime} 25^{\prime \prime} \mathrm{W}$; see Gillis et al. 2005a). Both boreal forest grids were dominated by white spruce forest (Picea glauca (Moench) Voss) and willow thickets (genus Salix L.) with occasional aspen stands (Populus tremuloides L.). In the low-elevation meadow site, data were collected at a 10-ha grid ( $\sim 800$ m a.s.1.) inside Kluane National Park and Reserve (KNPR), within south-facing meadow habitat surrounded by boreal forest east of the Slims River delta $\left(60^{\circ} 59^{\prime} 56^{\prime \prime} \mathrm{N}, 138^{\circ} 33^{\prime} 31^{\prime \prime} \mathrm{W}\right)$. The 9-ha alpine meadow grid ( $\sim 1600 \mathrm{~m}$ a.s.1.) was also situated in KNPR and approximately $8 \mathrm{~km}$ uphill from the low-elevation meadow site in the south-facing alpine meadow habitat $\left(61^{\circ} 01^{\prime} 06^{\prime \prime} \mathrm{N}, 138^{\circ} 37^{\prime} 34^{\prime \prime} \mathrm{W}\right)$. All four sites are described in detail by Donker and Krebs (2011).

\section{Trapping and handling}

At the boreal forest sites, squirrels were live trapped on two grids each with 50 traps spaced $30 \mathrm{~m}$ apart in a $10 \times 10$ pattern, with traps placed at alternate grid stations. At the low-elevation meadow site, squirrels were trapped on a grid with 50 traps spaced $50 \mathrm{~m}$ apart in a $5 \times 10$ pattern. At the alpine meadow site, squirrels were trapped on a grid with 49 traps spaced $50 \mathrm{~m}$ apart in a $7 \times 7$ pattern. Live traps $(14 \times 14 \times 40 \mathrm{~cm}$; Tomahawk Live Trap, Tomahawk, WI, USA) were baited with peanut butter. Upon first capture, squirrels were transferred to a mesh bag, tagged with Monel No. 1005-1 tags (National Band and Tag, Newport, KY, USA) in both ears, weighed, sexed and measured.

\section{Density}

Population density for all habitat types were obtained by mark-recapture methods. Each mark-recapture session consisted of between two (typically) and four (in situations of low AGS density) consecutive days of trapping in late July to early August. Traps were set at 0800 hours, checked every $1.5 \mathrm{~h}$ and closed by 1230 hours each trapping day. Arctic ground squirrels are highly trappable and recapture rates were high $(>80 \%)$. All density estimates were calculated using the maximum likelihood (ML) spatial model within the program Density version 4.4 using all the default parameters (Efford et al. 2009; http:/www.otago.ac.nz/density/, verified 16 April 2015). This model was selected because it provides superior density estimates for small mammals (C. J. Krebs, unpubl. data).

\section{Relative abundance}

In 2008 and 2009, we indexed 18 populations of AGS throughout a $4000-\mathrm{km}^{2}$ area in the Kluane region, Yukon. In 2013, we indexed an additional 140 sites over a $25000-\mathrm{km}^{2}$ area to increase our landscape perspective on the relative abundance of ground squirrels in all available habitats from the forest to the alpine ( 24 boreal forest habitats, 50 low-elevation meadows, 26 mid-elevation meadows, 30 alpine habitats and 28 areas under strong anthropogenic influence). We used a powder tracking methodology described by Hubbs et al. (2000). Small $(5 \times 7 \mathrm{~cm})$ black plastic tiles were placed in all known burrows in a specified area (minimum $0.5 \mathrm{ha}$ ) and left for $6 \mathrm{~h}$. The tiles were covered lightly in paraffin-based oil and unscented talcum powder. We retrieved the tiles and determined whether the burrow was active or inactive; if the tile was moved, covered in soil or showed tracks, the burrow was considered active. The area of each site indexed was determined by recording the global positioning system (GPS) coordinates of the corners of the site and then using MapSource (Garmin Corporation, Olathe, KS, USA; http://www8.garmin.com/, accessed 20 July 2013) to estimate the area in hectares (for details, see Donker and Krebs 2011). The area was used to calculate an estimate of active burrows per hectare and total burrows per hectare. In the event of a discrepancy between the number of tiles deployed and the number of tiles retrieved, the number of tiles deployed was used in the calculation of burrow density and the number of tiles retrieved was used to determine the density of active burrows. To minimise bias associated with juvenile emergence in mid-June and variation across sites, all locations were indexed between midMay and mid-June. Because the activity of AGS is influenced by both time of day and weather (Folk 1963), indexing was conducted between 0800 and 1600 hours each day during clear weather conditions.

\section{Translocations}

To determine whether meadow habitats serve as source populations that provide immigrants to the boreal forest, we 
first studied dispersal from occupied sites. Specifically, we radio-collared 17 juveniles from low-elevation meadow and alpine tundra habitats (34 total) at the trapping grids described previously. Dispersed juveniles from low-elevation meadows moved further ( $319 \pm 71$ vs $76 \pm 71 \mathrm{~m})$ and had lower survival (40\% vs 90\%) than juveniles dispersed from the alpine. Most juveniles from low-elevation meadows (11 of 17) moved into the boreal forest before being predated by raptors. We found no dispersal towards empty habitats at lower elevation sites in the forest (Donker 2010). Gillis (2003) suggested that the boreal forest may be a sink habitat for arctic ground squirrels.

To test the sink hypothesis more rigorously, in early July 2013 we moved 45 ground squirrels a distance of $7 \mathrm{~km}$ from the Burwash Airport $\left(61^{\circ} 22^{\prime} 5.85^{\prime \prime} \mathrm{N}, 139^{\circ} 1^{\prime} 43.10^{\prime \prime} \mathrm{W}\right)$ to the Duke River meadow site $\left(61^{\circ} 23^{\prime} 21.35^{\prime \prime} \mathrm{N}, 139^{\circ} 6^{\prime} 13.86^{\prime \prime} \mathrm{W}\right)$, a $5-\mathrm{km}^{2}$ habitat containing both forest and meadow where ground squirrels had formerly been abundant but were now extirpated (J. R. Werner, unpubl. data). The release group consisted of six adult males, 17 adult females, 15 juvenile males and seven juvenile females. At the introduction site we experimentally manipulated grass height and visibility (short grass and long grass treatments) and the number of burrows available. Treatment units were $50 \times 50 \mathrm{~m}$ in size, oriented in a $5 \times 10$ pattern (collectively treatments covered 12.5 ha of area) using a randomised block design, to maximise the use of available meadow. The entire experimental grid was trapped over four consecutive days, before reintroduction, during late June to confirm that it was without resident ground squirrels.

For the short grass treatment, vegetation height was reduced to $10 \mathrm{~cm}$ (range $0-23 \mathrm{~cm}$ ) using gas-powered string trimmers 2 weeks before the release of squirrels. The tall grass treatment consisted of un-manipulated grassland with a mean height of $94 \mathrm{~cm}$ (range 15-114 cm). The dried trimmings, which covered $<1 \%$ of the ground surface, were left in situ.

To manipulate burrow density, artificial burrows $(50 \mathrm{~cm}$ deep and $7 \mathrm{~cm}$ in diameter) were dug using a 1.5-horsepower gaspowered auger drill and a one-piece Edelman-style Dutch hand auger at a $30^{\circ}$ angle from ground surface (similar to Gedeon et al. 2011). The low density treatment was set at 50 burrows per hectare (approximating the number of natural burrows found in situ) and the high density treatment was raised to 200 burrows per hectare.

AGS were captured and released within $2 \mathrm{~h}$ of detainment. Individuals were fitted with 1.5-g radiotransmitters (Model PD-2C; Holohil Systems, Carp, Canada); juveniles were fitted with expandable collars to accommodate rapid growth (for collar construction, see Byrom 1997). Capture and transport coincided with the timing of peak activity (0600-1000 hours) observed during the previous week. To minimise social interactions with 'novel' individuals, the spatial arrangement among family groups (those trapped at the same burrows) at the release site mimicked the approximate arrangement at the capture site.

Radio-collared individuals were located using telemetry on alternating days from 7 July 2013 through to 20 August 2013 in order to estimate movement patterns and active season survival. Each time a squirrel was located, its exact position was recorded using a hand-held GPS receiver accurate to $\pm 5 \mathrm{~m}$. All collars were removed on 19-23 August 2013; translocated individuals were monitored into the autumn only by visual inspection.
In addition to our experimental reintroductions, we monitored the potential for natural dispersal by immigration at five additional extirpated sites in the surrounding area to determine whether any unmarked dispersers from other meadows would settle preferentially near the release area. These five meadows, which were of comparable size to the release site and within $2 \mathrm{~km}$ of the Duke system, were trapped over two consecutive days during June 2013 (using methods described above). These areas were subsequently monitored using repeat powder tracking every 14 days from 10 July 2013 to 10 September 2013. Burrow activity recorded in these meadows was interpreted to indicate that a dispersing animal had visited that site. Monitoring at the release site was supplemented with four camera traps (Reconyx model PC800; http://www.reconyx. com/shop/Professional_Research_Camera_Traps/56, verified 16 April 2015) that recorded still images at locations containing concentrations of telemetered animals. Cameras were placed on wooden stakes at a height of $1.2 \mathrm{~m}$ from the ground surface.

\section{Statistical analyses}

All statistical analyses were performed using JMP version 4.0 (SAS Institute, Cary, NC, USA). The significance of differences between average densities of AGS, number of burrows per hectare and number of active burrows per hectare between habitats was tested using one-way ANOVA with Tukey's post hoc tests. Prior to analysis, all data were assessed for normality and homogeneity of variance. Both density and relative abundance data did not meet the assumptions of normality and so were transformed. A log-transformation was applied to the density data and a square root transformation was applied to the relative abundance data to meet the assumptions of normality and equal variance. Standard errors for proportions were calculated using the Wilson score method (Newcombe 1998). All data are reported as the mean \pm s.e.

\section{Results}

\section{Density in the Kluane Lake region}

AGS density in the boreal forest underwent cyclic fluctuations from 1977 to 2000, following closely the snowshoe hare population cycle; after the population crash in 2000, AGS density remained low and did not subsequently recover (Fig. 2). From the 1970s through to the 1990s, the lowest density in the forest was approximately $0.5 \mathrm{ha}^{-1}$ in spring, typically rising to $\sim 1.5-2.5 \mathrm{ha}^{-1}$ in summer. After 1999, densities fell and have subsequently remained lower than $0.5 \mathrm{ha}^{-1}$, with most sites becoming locally extinct by 2009 . Ground squirrels now amount to approximately $3 \%$ of the herbivore energy flow in the boreal forest zone.

Conversely, AGS populations in the alpine tundra did not collapse (Donker 2010; Donker and Krebs 2011; Fig. 2) and were essentially identical in 1975-76 (Green 1977) and 2008-09 at $5-6 \mathrm{ha}^{-1}\left(5.8 \pm 0.5 \mathrm{ha}^{-1}\right.$ in 1976 and $1977,5.0 \pm 0.6 \mathrm{ha}^{-1}$ in 2008 and $6.1 \pm 0.7 \mathrm{ha}^{-1}$ in 2009; Fig. 2). In contrast, AGS densities in the low-elevation meadow site contained approximately 1.5 squirrels per hectare over 2008-09 $\left(1.25 \pm 0.22 \mathrm{ha}^{-1}\right.$ in 2008 and $1.6 \pm 0.3 \mathrm{ha}^{-1}$ in 2009), and many other low-elevation sites have gone extinct (see below). For example, areas of lowelevation meadow along the Duke River that were formerly 


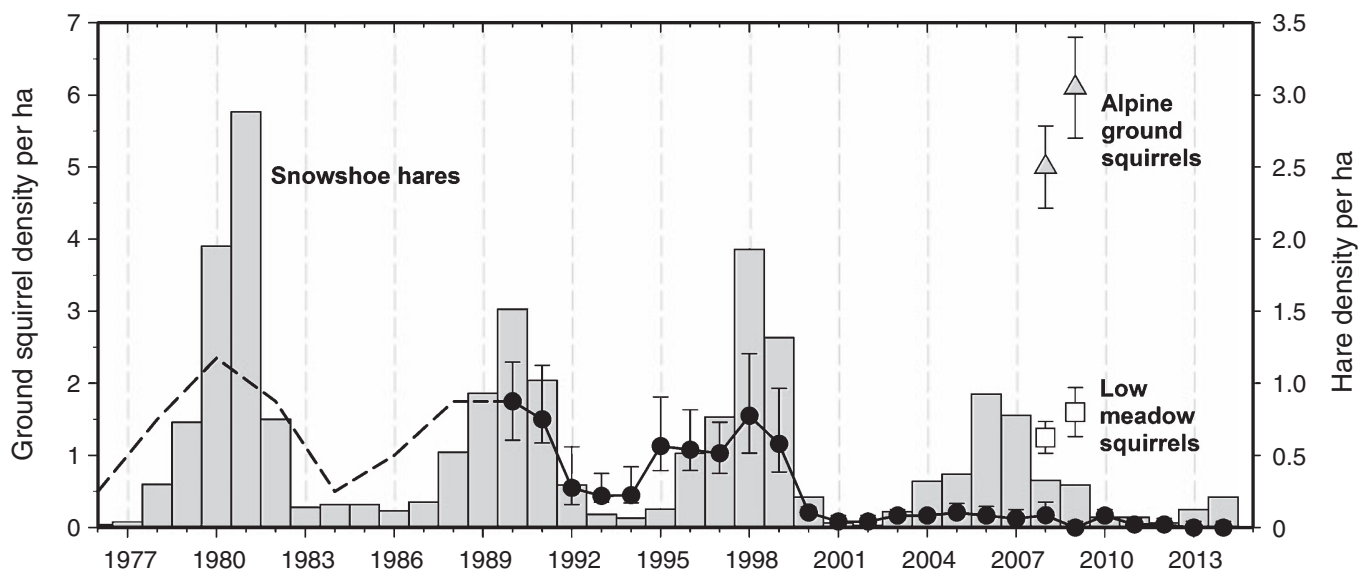

Fig. 2. Changes in the spring density of arctic ground squirrels in two live-trapping grids in the boreal forest at Kluane Lake since 1977 (filled circles) and the spring density of snowshoe hares in the same habitat (histograms). Densities of arctic ground squirrels in alpine tundra (shaded triangles) and low meadow (open squares) are from single live-trapping grids during spring 2008-09. Error bars are 95\% confidence levels.

used by Kluane First Nations as a favoured trapping area for fur and food were empty of ground squirrels by 2006 (G. Pope, $\mathrm{KFN}$, pers. comm.) and have not returned despite a voluntary moratorium on harvesting there.

\section{Relative abundance}

A total of 158 populations was indexed throughout the southwest Yukon from 2008 to 2009 and in 2013. Population density was greater in both open versus closed habitats and at higher elevations (Table 1). Occupancy rates of boreal forest sites was near zero $(4.2 \pm 0.6 \%)$, and many low-elevation meadow sites are locally extirpated (occupancy $=44.8 \pm 6.8 \%$ ), whereas midand high-elevation populations exhibit relatively high occupancy rates $(77.6 \pm 7.9 \%$ and $93.3 \pm 5.0 \%$, respectively). We found that the regional densities showed a similar pattern to our intensively live-trapped areas around Kluane lake. The number of active burrows per hectare (including those at inactive colonies) increased from $2.91 \pm 1.21$ in boreal forest to $93.03 \pm 17.85$ in low-elevation meadow to $99.67 \pm 20.70$ in mid-elevation meadow, and $207.67 \pm 61.44$ in alpine tundra habitats $\left(F_{(4,146)}=28.62, P<0.0001\right)$. A post hoc Tukey test showed that boreal forests had significantly fewer burrows per hectare compared with all other habitats $(P<0.05)$ and that the alpine habitat had significantly more burrows per hectare than the low meadow habitats $(P<0.05)$. An anomaly in this pattern of increasing burrow activity with elevation must be noted: ground squirrels have remained in high abundance (143 \pm 27 active burrows per hectare; Table 1) along the margin of airports (Burwash Landing, Haines Junction, Silver City and Whitehorse) and are reported as abundant by farmers in the Whitehorse region and in enclosed grazing land at the Yukon Wildlife Preserve outside Whitehorse. The only ecological distinction of these diverse areas is that they have a considerable amount of human activity. In some cases, such as pasture land, the natural herbivore (snowshoe hares) has been replaced by larger vertebrates (e.g. cattle, bison); in other cases, such as along aircraft runways, grass height is kept low by mechanical cutting during the growing season.
Table 1. Relative abundance of arctic ground squirrels (Urocitellus parryii plesius) in five distinct habitat types from 2008 to 2013 throughout the south-west Yukon

Unless indicated otherwise, data are given as the mean \pm s.e. The density index is a measure of burrow activity using powder track methods described for this species by Hubbs et al. (2000). Occupancy is the percentage of colony sites of that habitat type that recorded a positive density index

\begin{tabular}{lcccc}
\hline Habitat & $\begin{array}{c}\text { No. } \\
\text { colonies }\end{array}$ & $\begin{array}{c}\text { Density index (active } \\
\text { burrows per hectare) }\end{array}$ & $\begin{array}{c}\text { Occupancy } \\
(\%)\end{array}$ & $\begin{array}{c}\text { Elevation } \\
(\mathrm{m})\end{array}$ \\
\hline Boreal forest & 24 & $2.91 \pm 1.21$ & $4.2 \pm 0.6$ & $500-900$ \\
Low meadow & 50 & $93.03 \pm 17.85$ & $44.8 \pm 6.8$ & $500-1000$ \\
Mid meadow & 26 & $99.67 \pm 20.70$ & $74.6 \pm 7.9$ & $1000-1500$ \\
Alpine & 30 & $207.67 \pm 61.44$ & $93.3 \pm 5.0$ & $1500-2100$ \\
Anthropogenic & 28 & $127.43 \pm 32.85$ & $96.5 \pm 4.4$ & $500-900$ \\
\hline
\end{tabular}

\section{Translocations}

After ground squirrels were released, $60 \%(n=45)$ left the 12.5 -ha treatment area and moved into forest or dense shrub cover. Of those that did not disperse into forest, most displayed either an aversion to the release site (24\%), despite the provision of short grass and burrow shelters, or exhibited transient visitations to the treatment (16\%) from other portions of the Duke River meadow system. Short-term survival (7 July-20 August) of translocated ground squirrels was low ( $20 \%)$. All 27 squirrels that settled in forested or shrub habitats were killed by predators within 60 days after release. Eight animals eventually settled in or near the treatment blocks or the surrounding buffer and survived throughout the summer.

By late July 2013, the first records of new unmarked colonisers were obtained from camera traps positioned at active burrow complexes on or surrounding the treatment grids. Twelve immigrants were identified visually at the release site and subsequently trapped and marked. Of these new recruits, three adult males were captured and collared for monitoring purposes. These immigrants were observed regularly throughout the season. Regular monitoring of the five nearby control plots (to monitor immigration) in the Duke River meadow system 
indicated that four of the five remained unoccupied all summer. Transient burrow activity was recorded during July at one of these control sites, but by mid-September the site was once again empty, despite the presence of adequate forage and natural burrow shelter. None of the translocated squirrels survived overwinter to spring 2014. In this experiment, we failed to successfully recolonise an area historically known as highquality habitat.

\section{Discussion}

That the initial decline of AGS populations in 2000 coincided with the decline phase of the hare cycle points to predation, acting directly on summer survival, as the likely cause of population collapse. It is less clear what mechanisms are behind the persistent low density (2000-present) and local extirpations in all lowelevation habitats (Gillis et al. 2005a; Donker and Krebs 2011; J. R. Werner, unpubl. obs.). In addition to predation, climatic warming may cause hibernacula to become flooded when midwinter rains occur, leading to high overwinter mortality. This hypothesis could be catastrophic, occurring in only one year, or it could be continual over a series of winters. Possible top-down forces (both direct (killing) and indirect (non-lethal) effects of predation) maintaining low squirrel density are predicted to operate on survival and reproduction during the summer months. In contrast, bottom-up processes (catastrophic snow melt being a likely scenario) are predicted to have a pronounced effect on hibernation success in winter. Given the large-scale collapse of AGS populations at low elevations, it is also critical to understand whether AGS possess the ability to immigrate into and recolonise extinct sites, thus allowing populations to recover.

\section{Predation}

Hik et al. (2001) found that AGS were more chronically stressed in boreal forest than in continuous alpine and attributed this to the sublethal effects of higher predator numbers and reduced ability of AGS to detect predators within forested areas. Direct comparisons of high alpine and low forest sites were also made by Gillis et al. (2005a), who found that AGS in the boreal forest exhibited negative population growth, primarily due to low active season survival. These findings prompted an investigation into the possible existence of source-sink dynamics between lowelevation meadows and the intervening forest (Donker and Krebs 2012). That study was the first to compare populations in proximity, thereby controlling for the many confounding factors inherent in comparing populations across elevations (e.g. Green 1977; Hik et al. 2001; Gillis et al. 2005a; Sheriff et al. 2012). Substantive evidence for source-sink dynamics was found in that forests had negative population growth, low-elevation meadows had positive population growth and low-elevation meadows exported dispersing juveniles into the adjacent boreal forest (Donker and Krebs 2012).

Our present understanding of AGS population dynamics in the Kluane region leaves little doubt that predation played a key role in maintaining and synchronising population cycles of ground squirrels and snowshoe hares (cf. Boutin et al. 1995; Karels and Boonstra 1999). However, it is precisely this historical cyclicity that obfuscates the interpretation of previous studies and the relevance of those findings to all phases of the cycle or to the present non-cyclical conditions. Both a strong demographic Allee effect (Courchamp et al. 2008) and the existence of a predator pit (May 1977) would explain the lack of recovery after a rapid decline. In the case where the mortality agents are generalist predators (Type II functional response) Allee effects predict population instability and increased probability of extinction. In the case where specialist predators switch between alternative prey (Type III functional response), a stable low-density 'refuge' exists and persistence is possible (Sinclair et al. 1998).

\section{Climate change}

The deleterious effects of excess moisture on overwinter survival will depend on how well burrow systems are designed to protect hibernating individuals from flooding events. It must be noted that the type of flooding whose effects are sufficiently widespread to bring about a significant decrease in regional population size can only be caused by rain-on-snow events. River flooding of the type described by Carl (1971) is restricted to habitats directly adjacent to waterways and, in a topographically diverse area like Kluane, riverbanks comprise a miniscule proportion of the habitat occupied by AGS.

Many ground squirrel species survive in relatively moist climates, where flooding is presumably a greater threat than the steppe-tundra in which AGS have resided for over one million years. Almost nothing is known of the specific structure of hibernation burrow systems or of their capacity to mitigate flooding. However, Shaw (1926) describes complex drainage channels designed to draw moisture away from hibernation chambers of Columbian ground squirrels. We propose that sumps are likely a common feature of the hibernacula of other ground squirrel species whose hibernation chambers are situated in poorly drained terrain (flat hill slopes; Shaw 1926) and that these drainage features are an effective floodmitigation technique. We find no reports of flood-induced regional population collapses of ground squirrels in the literature.

The climate-flooding hypothesis is predicated on the condition that AGS are more vulnerable to excess moisture than other ground-dwelling squirrels. Therefore, a key prediction is that AGS hibernacula will lack adequate drainage tunnels to withstand surplus moisture caused by rapid snowmelt. Given their long evolutionary history ( $>1$ million years) in the cold and arid Nearctic (Eddingsaas et al. 2004), we view this loss of flood protection as distinctly possible. However, if hibernation burrows do contain drainage structures, AGS should be no more vulnerable than their southern heterospecific counterparts.

\section{Recovery limitations}

Given that localised extirpations are now extensive, key questions concerning the likelihood of recovery in the montane boreal are whether and how low-elevation meadows will provide sufficient immigrants to repopulate extinct locales, and whether unoccupied forested habitats can support population growth. Fig. 3 is a hierarchical constitutive conceptual model to explain the prolonged low phase illustrated in Fig. 2 (2000-present) and the lack of translocation success. As such, it is intended to lend coherence to future investigations of the present topic. The first question is whether dispersal occurs between populations. Most of the literature on arctic ground squirrels demonstrates strong 


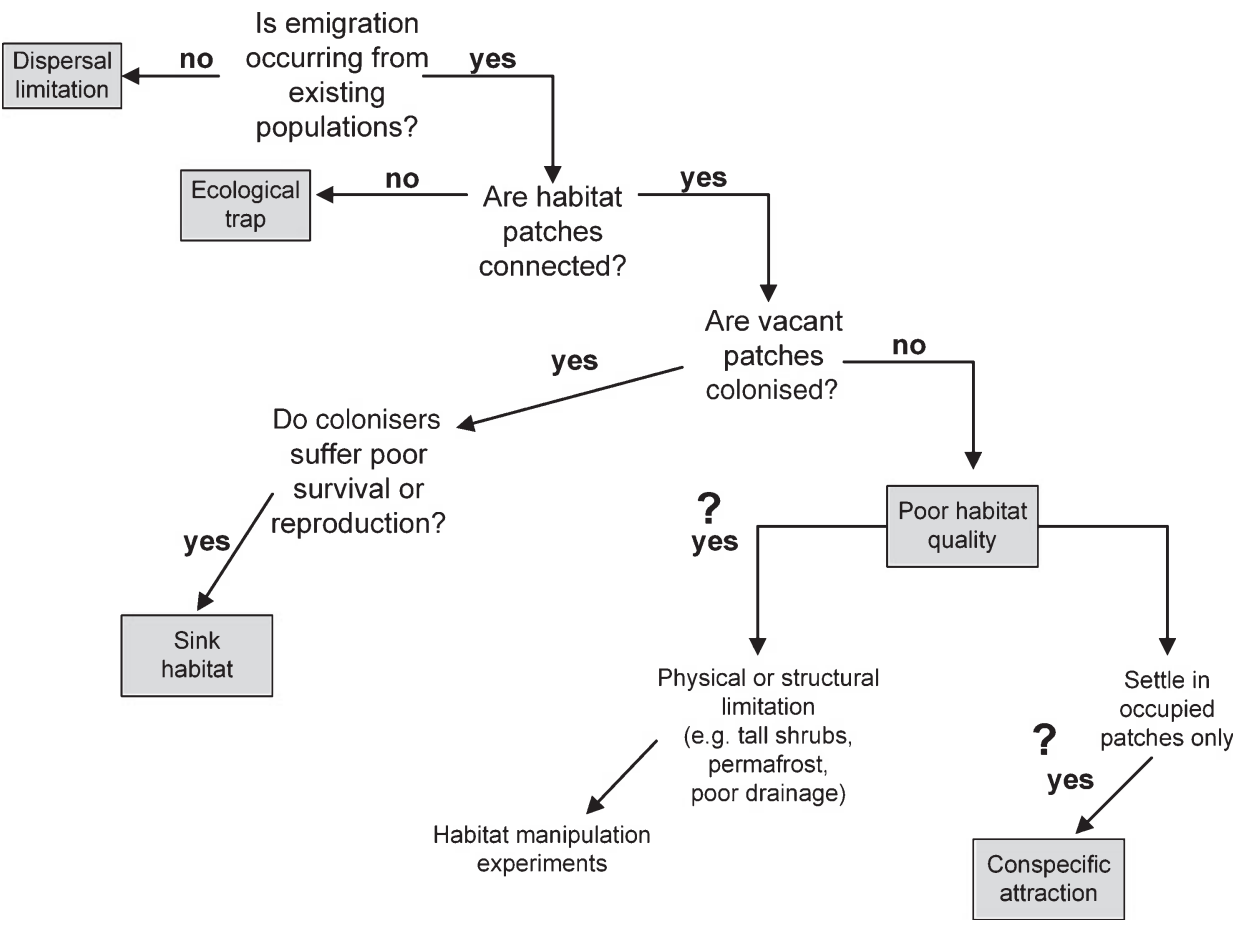

Fig. 3. Conceptual decision tree to test for the limiting factor in arctic ground squirrel population collapses and lack of recovery over a 16-year period (1998-present).

tendencies to disperse, particularly for males (Byrom and Krebs 1999; Karels and Boonstra 1999; Gillis 2003). It is unlikely that dispersal limitation operates in this system. The second question is whether habitat patches are connected. The habitats around Kluane have no obvious metapopulation structure, and there would appear to be little possibility of an ecological trap (Schlaepfer et al. 2002) operating over the large spatial scale of this study. The third key question is whether vacant habitat patches are colonised. The answer to this can be both yes and no, and it is this key question that needs further discussion. We have been monitoring 10 vacant meadows since 2010 in the Kluane region and, as yet, have not observed a recolonisation event. Our motivation to experimentally translocate individuals was, therefore, prompted by ostensibly poor recolonisation success.

Burrows are a key resource for ground squirrels (Carl 1971) and could be a limiting factor. However, this is unlikely because the density of burrows remains at over $200 \mathrm{ha}^{-1}$ at sites in the forest and over $600 \mathrm{ha}^{-1}$ in the alpine. Burrows collapse slowly when not used and they remain as clear marks in the landscape for more than 25 years (Karels and Boonstra 1999; J. R. Werner, unpubl. obs.).

When considering species in heterogeneous habitats, it is necessary to address the role of habitat quality in determining dispersal rates between patches and the occupancy status of a patch at any given time (Pulliam and Danielson 1991). 'Sources' are net exporters of individuals. In these high-quality habitats, natality exceeds mortality and connectivity with other habitat patches facilitates successful dispersal. In poor-quality habitat or sink habitats, local yearly recruitment as driven by reproduction and survival of the patch residents is too low to sustain the population. Sink habitats are net importers and, without sufficient immigration, extinction would be inevitable. Source-sink theory is becoming increasingly nuanced in order to accommodate a growing number of empirical studies that have identified this patch dynamic in natural systems (Loreau et al. 2013). The simple 'two patch' model is being replaced with scale- and context-specific definitions (e.g. Watkinson and Sutherland 1995) intended to explain the demographic causes and consequences of spatial movements of individuals across populations. For example, a source or sink can be 'conditional' or 'unconditional' (Loreau et al. 2013) depending on its intrinsic propensity to produce or absorb individuals. A source habitat may become a sink (and vice versa) over relatively short temporal scales (Boughton 1999). In certain cases, a population may even fluctuate in and out of source-sink dynamic in a short period of time.

Source-sink theory necessarily equates habitat preference with habitat quality. Patch models assume that individuals settle in the best habitat until it fills up, with the excess being forced to settle in the inferior habitat. Therefore, optimal habitat selection leads to stable population dynamics, with high population growth at low densities when nearly all individuals can settle in good habitat (Battin 2004).

For AGS the key question remaining to be answered in the decision tree (Fig. 3 ) is whether vacant patches are colonised. One underlying question here is what defines a suitable vacant patch. There is a tendency to view this question as relating to food plants and burrow sites for ground squirrels, but an important qualification for AGS is whether there is conspecific attraction such that a suitable vacant area becomes attractive only when it is already occupied by other squirrels (Weddell 1991; Reed and Dobson 1993). Weddell (1991) showed how Columbian ground 
squirrels will not settle in suitable habitat unless there are other squirrels already present. The observed fates of both translocated and radio-collared AGS in situ are consistent with the predation hypothesis. However, observations of unmarked immigrants after, but not before, the translocation, and to occupied but not vacant meadows, points to the possibility that the suitability of a patch (from the perspective of a dispersing individual) is at least partially associated with its occupancy status. This question may be partially tested with recorded calls of ground squirrels from a tape player, or by placing caged individuals in previously unoccupied habitats and quantifying visitation rates and/or settlement behaviours of dispersing immigrants.

Ground squirrels have a kin-related social structure in which females rarely disperse and males always disperse (Lacey 1991; Gillis 2003). Thus, colonies of ground squirrels are composed of a group of related females and immigrant males. The presumed selective advantage of this social structure is based partly on alarm calls, but more detailed studies in this species are needed to confirm the common belief that the alarm call is aimed at conspecifics rather than at the predator (Digweed and Rendall 2009). Male AGS are infanticidal and kin groups of females may help repel these males and improve juvenile survival (Sherman 1981; McLean 1983). A series of critical experiments is needed to sort out competing hypotheses about the use and consequences of alarm calls in this species.

\section{Future work}

During the next 2 years we intend to replicate the introduction experiments of AGS into areas they formerly occupied and to determine whether they are able to escape the predator pit they currently appear to be in. Our working hypothesis is that they show an Allee effect in which densities below $\sim 0.5 \mathrm{ha}^{-1}$ cannot be sustained because of a lack of sufficient alarm calls to reduce predation mortality. In the boreal forest, shrub density has increased due to reduced browsing by snowshoe hares, and shrub density prevents ground squirrels from seeing approaching predators. A key threatening process in this ecosystem is predation, and successful predation is modulated by the likelihood of predator detection in dense habitats. Recent attenuation of the hare cycle and milder winter climate have allowed shrubs to expand throughout the forest region, resulting in reduced visibility and increased predation risk within the forest.

This explanation predicts that the recovery and range expansion of the AGS will first occur in open meadow habitats and in areas such as roadsides and farmland cleared by human activities. These areas will serve as source populations for forest areas but, if forest habitats remain as sinks (Gillis et al. 2005b; Donker and Krebs 2011), forest populations of ground squirrels may never recover. This research serves to highlight changes occurring to Canada's montane boreal ecosystem. The challenges to identifying causes of population decline and barriers to future recovery are best met by addressing multiple hypotheses simultaneously.

\section{Acknowledgements}

The authors thank Lance Goodwin and Sian Williams of the Arctic Institute of North America's Kluane Lake Station for providing facilities and assistance. Keenan Peddie, Isabel Shinnick-Gordon, Shelby Harkless,
Michael Champion, Chris Baird, Tianna Sturdy and Michelle Connolly assisted in the collection of data in the field. Funding was provided from the Natural Science and Engineering Research Council of Canada, the Yukon Fish and Wildlife Enhancement Trust, the Northern Science Training Program of Environment Canada (administered by the University of British Columbia), The W. Garfield Weston Foundation Fellowship Program (a program of the Wildlife Conservation Society Canada funded by The W. Garfield Weston Foundation), the Northern Research Endowment fund (administered by Yukon College), a grant-in-aid from the Arctic Institute of North America and logistical support from Yukon Territorial government and Parks Canada. The authors are also grateful to Parks Canada, the Champagne-Aishihik First Nation and the Kluane First Nation for allowing us to conduct our research within Kluane National Park and within First Nation traditional territory.

\section{References}

Battin, J. (2004). When good animals love bad habitats: ecological traps and the conservation of animal populations. Conservation Biology 18, 1482-1491. doi:10.1111/j.1523-1739.2004.00417.x

Batzli, G. O., and Sobaski, S. T. (1980). Distribution, abundance, and foraging patterns of ground squirrels near Atkasook, Alaska. Arctic and Alpine Research 12, 501-510. doi:10.2307/1550497

Boughton, D. A. (1999). Empirical evidence for complex source-sink dynamics with alternative states in a butterfly metapopulation. Ecology 80, 2727-2739.

Boutin, S., Krebs,, C. J., Boonstra, R., Dale, M. R. T., Hannon, S. J., Martin, K., Sinclair, A. R. E., Smith, J. N. M., Turkington, R., Blower, M., Byrom, A., Doyle, F. I., Doyle, C., Hik, D., Hofer, L., Hubbs, A., Karels, T., Murray, D.L, Nams, V., O'Donoghue, M., Rohner, C., and Schweiger, S. (1995). Population changes of the vertebrate community during a snowshoe hare cycle in Canada's boreal forest. Oikos 74, 69-80. doi: $10.2307 / 3545676$

Buck, C. L., and Barnes, B. M. (1999). Annual cycle of body composition and hibernation in free-living arctic ground squirrels. Journal of Mammalogy 80, 430-442. doi:10.2307/1383291

Byrom, A. E. (1997) 'Population Ecology of Arctic Ground Squirrels in the Boreal Forest During the Decline and Low Phases of a Snowshoe Hare Cycle.' (University of British Columbia: Vancouver.)

Byrom, A. E., and Krebs, C. J. (1999). Natal dispersal of juvenile arctic ground squirrels in the boreal forest. Canadian Journal of Zoology 77, 1048-1059. doi:10.1139/z99-072

Byrom, A. E., Karels, T. J., Krebs, C. J., and Boonstra, R. (2000). Experimental manipulation of predation and food supply of arctic ground squirrels in the boreal forest. Canadian Journal of Zoology $\mathbf{7 8}$, 1309-1319. doi:10.1139/z00-055

Carl, E. A. (1971). Population control in arctic ground squirrels. Ecology 52, 395-413. doi: $10.2307 / 1937623$

Courchamp, F., Berec, L., and Gascoigne, J. (2008) 'Allee Effects in Ecology and Conservation.' (Oxford University Press, Oxford.)

Digweed, S. M., and Rendall, D. (2009). Predator-associated vocalizations in North American red squirrels, Tamiasciurus hudsonicus: are alarm calls predator specific? Animal Behaviour 78, 1135-1144. doi:10.1016/j. anbehav.2009.07.030

Donker, S. A. (2010) Arctic ground squirrels in the southwest Yukon territory: evidence for habitat specific demography and source-sink dynamics. M. Sc. Thesis, University of British Columbia, Vancouver.

Donker, S. A., and Krebs, C. J. (2011). Habitat specific distribution and abundance of arctic ground squirrels (Urocitellus parryii plesius) in southwest Yukon. Canadian Journal of Zoology 89, 570-576. doi:10.1139/z11-041

Donker, S. A., and Krebs, C. J. (2012). Evidence for source-sink dynamics in a regional population of arctic ground squirrels (Urocitellus parryii plesius). Wildlife Research 39, 163-170. doi:10.1071/WR11167

Eddingsaas, A. A., Jacobsen, B. K., Lessa, E. P., and Cook, J. A. (2004). Evolutionary history of the arctic ground squirrel (Spermophilus parryii) 
in Nearctic Beringia. Journal of Mammalogy 85, 601-610. doi:10.1644/ BRB-204

Efford, M. G., Borchers, D. L., and Byrom, A. E. (2009). Modeling demographic processes in marked populations. In 'Modeling Demographic Processes in Marked Populations'. (Eds D. L. Thomson, E. G. Cooch and M. J. Conroy.) pp. 255-269. (Springer: New York.)

Folk, M. A. (1963). The daily distribution of sleep and wakefulness in the Arctic ground squirrel. Journal of Mammalogy 44, 575-577. doi:10.2307/1377144

Gedeon, C. I., Váczi, O., Koósz, B., and Altbäcker, V. (2011). Morning release into artificial burrows with retention caps facilitates success of European ground squirrel (Spermophilus citellus) translocations. European Journal of Wildlife Research 57, 1101-1105. doi:10.1007/ s10344-011-0504-3

Gillis, E. A. (2003). Breeding dispersal, male mating tactics, and population dynamics of arctic ground squirrels. Ph.D. Thesis, University of British Columbia, Vancouver.

Gillis, E. A., Hik, D. S., Boonstra, R., Karels, T. J., and Krebs, C. J. (2005a). Being high is better: effects of elevation and habitat on arctic ground squirrel demography. Oikos 108, 231-240. doi:10.1111/j.00301299.2005.13535.x

Gillis, E. A., Morrison, S. F., Zazula, G. D., and Hik, D. S. (2005b). Evidence for selective caching by arctic ground squirrels living in alpine meadows in the Yukon. Arctic 58, 354-360.

Green, J. E. (1977). Population regulation and annual cycles of activity and dispersal in the arctic ground squirrel. M.Sc. Thesis, University of British Columbia, Vancouver.

Hubbs, A. H., and Boonstra, R. (1997). Population limitation in Arctic ground squirrels: effects of food and predation. Journal of Animal Ecology 66, 527-541. doi: $10.2307 / 5947$

Hubbs, A. H., Karels, T. J., and Boonstra, R. (2000). Indices of population size for burrowing mammals. The Journal of Wildlife Management 64, 296-301. doi: $10.2307 / 3803002$

Hik, D. S., McColl, C. J., and Boonstra, R. (2001). Why are Arctic ground squirrels more stressed in the boreal forest than in alpine meadows? Ecoscience 8, 275-288.

IUCN (2008). 'IUCN Red List of Threatened Species.' Available at http:// www.iucnredlist.org/details/20488/0 [verified 8 November 2014].

Karels, T. J., and Boonstra, R. (1999). The impact of predation on burrow use by Arctic ground squirrels in the boreal forest. Proceedings of the Royal Society of London Series B, Biological Sciences 266, 2117-2123. doi:10.1098/rspb.1999.0896

Karels, T. J., and Boonstra, R. (2000). Concurrent density dependence and independence in populations of arctic ground squirrels. Nature $\mathbf{4 0 8}$, 460-463. doi: $10.1038 / 35044064$

Karels, T. J., Byrom, A. E., Boonstra, R., and Krebs, C. J. (2000). The interactive effects of food and predators on reproduction and overwinter survival of arctic ground squirrels. Journal of Animal Ecology 69, 235-247. doi:10.1046/j.1365-2656.2000.00387.x

Krebs, C. J. (2001). General introduction. In 'Ecosystem Dynamics of the Boreal Forest'. (Eds C. J. Krebs, S. Boutin and R. Boonstra.) pp. 3-24. (Oxford University Press: New York.)

Krebs, C. J., Boonstra, R., Boutin, S., Sinclair, A. R. E., Smith, J. N. M., Gilbert, B. S., Martin, K., O’Donoghue, M., and Turkington, R. (2014). Trophic dynamics of the boreal forests of the Kluane Region. Arctic 67, 71-81. doi:10.14430/arctic4350

Lacey, E. A. (1991). Reproductive and dispersal strategies of male arctic ground squirrels (Spermophilus parryii plesius). Ph.D. Thesis, University of Michigan, Ann Arbor.

Loreau, M., Daufresne, T., Gonzalez, A., Gravel, D., Guichard, F., Leroux, S. J., Loeuille, N., Massol, F., and Mouquet, N. (2013). Unifying sources and sinks in ecology and earth sciences. Biological Reviews of the Cambridge Philosophical Society 88, 365-379. doi:10.1111/brv.12003

May, R. M. (1977). Thresholds and breakpoints in ecosystems with a multiplicity of stable states. Nature 269, 471-477. doi:10.1038/269471a0

McLean, I. G. (1981) 'Social Ecology of the Arctic Ground Squirrel Spermophilus parryii.' (University of Alberta: Edmonton.)

McLean, I. G. (1983). Paternal behaviour and the killing of young in arctic ground squirrels. Animal Behaviour 31, 32-44. doi:10.1016/S0003-3472 (83) $80171-7$

Newcombe, R. G. (1998). Two-sided confidence intervals for the single proportion: comparison of seven methods. Statistics in Medicine 17, 857-872. doi:10.1002/(SICI)1097-0258(19980430)17:8<857::AID-SIM 777>3.0.CO;2-E

Pulliam, H. R., and Danielson, B. J. (1991). Sources, sinks, and habitat selection: a landscape perspective on population dynamics. American Naturalist 137, S50-S66. doi:10.1086/285139

Reed, J. M., and Dobson, A. P. (1993). Behavioural constraints and conservation biology: conspecific attraction and recruitment. Trends in Ecology \& Evolution 8, 253-256. doi:10.1016/0169-5347(93)90201-Y

Schlaepfer, M. A., Runge, M. C., and Sherman, P. W. (2002). Ecological and evolutionary traps. Trends in Ecology \& Evolution 17, 474-480. doi:10.1016/S0169-5347(02)02580-6

Shaw, W. T. (1926). Age of the animal and slope of the ground surface, factors modifying the structure of hibernation dens of ground squirrels. Journal of Mammalogy 7, 91-96. doi:10.2307/1373674

Sheriff, M. J., Kenagy, G. J., Richter, M. M., Lee, T., Tøien, Ø., Kohl, F., Buck, C. L., and Barnes, B. M. (2011). Phenological variation in annual timing of hibernation and breeding in nearby populations of Arctic ground squirrels. Proceedings of the Royal Society of London Series B, Biological Sciences 278, 2369-2375. doi:10.1098/rspb.2010.2482

Sheriff, M. J., Wheeler, H., Donker, S. A., Krebs, C. J., Palme, R., Hik, D. S., and Boonstra, R. (2012). Mountain-top and valley-bottom experiences: the stress axis as an integrator of environmentla variability in arctic ground squirrel populations. Journal of Zoology 287, 65-75. doi:10.1111/j.14697998.2011.00888.x

Sheriff, M. J., Richter, M. M., Buck, C. L., and Barnes, B. M. (2013). Changing seasonality and phenological responses of free-living male arctic ground squirrels: the importance of sex. Philosophical Transactions of the Royal Society of London Series B, Biological Sciences 368, 20120480. doi:10.1098/rstb.2012.0480

Sherman, P. W. (1981). Reproductive competition and infanticide in Belding's ground squirrels and other animals. In: 'Natural Selection and Social Behavior'. (Eds R. D. Alexander and D. W. Tinkle.) pp. 311-331. (Aldine Publishers: New York.)

Sinclair, A. R. E., Pech, R. P., Dickman, C. R., Hik, D., Mahon, P., and Newsome, A. E. (1998). Predicting effects of predation on conservation of endangered prey. Conservation Biology 12, 564-575. doi:10.1046/ j.1523-1739.1998.97030.x

Watkinson, A. R., and Sutherland, W. J. (1995). Sources, sinks and pseudosinks. Journal of Animal Ecology 64, 126-130. doi:10.2307/5833

Weddell, B. J. (1991). Distribution and movements of Columbian ground squirrels (Spermophilus columbianus (Ord)): are habitat patches like islands? Journal of Biogeography 18, 385-394. doi:10.2307/2845480

Wheeler, H. C. (2012). Population, individual and behavioural approaches to understanding the implications of habitat change for arctic ground squirrels. Ph.D. Thesis, University of Alberta, Edmonton.

Wheeler, H. C., and Hik, D. S. (2012). Arctic ground squirrels Urocitellus parryii as drivers and indicators of change in northern ecosystems. Mammal Review 43, 238-255. doi:10.1111/j.1365-2907.2012.00220.x 